Source. This must be noted for the work is unconventional in format. It contains but three chapters: "Overview", "Question Set" (sic) and "Annotated and Illustrated Bibliography". Chapter 1 covers the mineralogy and chemistry of clays, but ranges widely from Bouma sequences to ichnofacies. The second deals with methods for analysing shales, ranging from descriptions of the measurement of a section to the reflectance of phytoclasts. Fifteen colour photomicrographs illustrate various shale microfacies.

It is the third chapter that is unconventional. This takes up over half of the book and consists of an annotated and illustrated reference list. It is divided into sections with headings ranging from "Books, Classics and Classification" to "Shales as Hosts for Metallic Minerals" and "Environmental and Engineering Geology". Within each section the authors have arranged alphabetically references which they deem to be significant.

A sentence or, at the most, a paragraph explains the relevance of each reference, and key illustrations are reproduced from the original papers. This is a novel and painless way of "writing" a book. There may be some customer resistance to buying a volume which is largely an annotated bibliography - many geologists may prefer to use GeoAbstracts or a computerbased literature retrieval system. For those who do not, Sedimentology of Shale will prove to be an essential source book; pity, though, that with three authors "desiccation" is misspelt throughout.

Of Reineck and Singh's Depositional Sedimentary Environments there is far less to say. The first edition appeared in 1973 and rapidly became established as the definitive work on recent terrigenous sedimentary processes, structures and environments. The standard of the second edition ensures that it will maintain this position. A major re-write has not been attempted, but the book has been updated throughout and sections have been added to each chapter on ancient environments. Nonetheless, the main emphasis of the book remains on recent terrigenous sediments.

R.C. Selley is Reader in Petroleum Geology at Imperial College, University of London.

\title{
From the abyss to the lecture theatre
}

\section{Peter J. Smith}

Marine Geology. By James P. Kennett. Pp.813. ISBN 0-13-556936-2. (PrenticeHall: 1982.) \$34.95, £26.20.

No DISRESPECT to Professor Kennett, but in one sense this huge volume is alarming. For only three decades ago hardly any of it could have been written. Only during the past 20 years or so has the vaguely peripheral topic of marine geology moved to centre stage as Marine Geology - and with such vengeance that it is now possible for Kennett to write a textbook of an astonishing 813 pages at the comparatively lowly undergraduate-early-graduate level.

What made the rise of marine geology possible was the development of the appropriate exploration techniques; but what has made it matter is the discovery of the oceanic lithosphere's central role in the plate tectonics story and the consequent realization that the ocean floor's evolution is altogether more complex and interesting than that of a passive sedimentary dumping ground of great antiquity. Holism is the keyword here; and despite the need to become expert in a bewildering variety of subdisciplines, Kennett is wise enough not to allow his presentation to disintegrate into its constituent elements.

Of course, the parts are important; and in a teaching text it is essential that they be dealt with in some detail. Thus well over half of the volume is devoted to the basics of ocean morphology, marine stratigraphy and correlation, the current plate tectonic framework, crustal structure, sea-level changes, ocean margin processes, sediments and their microfossil loads, and so on. The extended climax of the book, however, is a long three-chapter section on palaeoceanography - a splendid synthesis of almost everything we know, or think we know, about how the ocean system has evolved.

This is the first major textbook on marine geology to appear since the plate tectonics revolution, although others are in progress in what could turn out to be a small publishing growth area during the 1980s. Because so much of the material is new and far from all of it has become part of the consensus, the book is necessarily referenced to an extent that undergraduates will find unusual, and perhaps even distracting, but graduates will find helpful. On the whole, Kennett has achieved a reasonable compromise between the need to attribute and the desire to find a lucid instructional style. The book is clearly intended chiefly for advanced undergraduates in the marine geology courses now springing up in the more forward-looking universities and colleges; but in view of the subject's crucial importance to all geology, it will prove indispensable to earth scientists at much higher levels and of all persuasions. Potential competitors will be hard pressed to improve on it.

Peter J. Smith is Reader in the Department of Earth Sciences at the Open University, Milton Keynes, and editor of Open Earth.

\section{Soils: their genesis and physics}

\section{David Rimmer \& Michael Adey}

The Soil Resource: Origin and Behavior. By Hans Jenny. Pp.377. ISBN 0-38790453-X. (Springer-Verlag: 1981.) DM57, $\$ 33.70$. Fundamentals of Soil Physics. By Daniel Hillel. Pp.430. ISBN 0-12-348560-6. (Academic: 1980.) \$40, £26.40. Applications of Soil Physics. By Daniel Hillel. Pp.385. ISBN 0-12-348580-0. (Academic: 1980.) $\$ 40, £ 26.40$.

IT IS now 40 years since the publication of Hans Jenny's classic monograph Factors of Soil Formation (McGraw-Hill, 1941), a book which provided the framework for much subsequent work in soil genesis. Now in his eighties, Jenny has written what amounts to a sequel to that earlier work. In it he develops his ideas into a broader, ecological view, describing how, by analysis of the "state factors", either whole ecosystems or their separate components vegetation, animals and soil - evolve with time and vary from place to place. This treatment occupies the second half of the book and is preceded by a consideration of the processes of soil genesis (water balance, ion exchange, clay formation, for example).

Jenny draws many of his examples from his own work and that of his students and colleagues. His use of the English language is unconventional; for example, he talks of "swarms" of ions around particles, "particle bondage with humus" and words like "porositors" and "depauperizes" appear. In addition the editors have purposely retained many of the original drawings which he made for the diagrams and figures, in order "to carry through the artistic touch". So what one gets overall is a very personal, even idiosyncratic, view of the soil resource. Although written in a textbook style, and in part intended for students, one would not recommend this as an undergraduate text. However the second part of the book particularly will be of interest to the many soil scientists who have been influenced, directly or indirectly, by the ideas of Hans Jenny.

In recent years a number of texts on soil physics have been published, rectifying the absence of much choice which had existed for some time. Fundamentals of Soil Physics together with its companion volume Applications of Soil Physics further extends the range of material in a most comprehensive way. Whilst each is a separate, self-contained volume, the latter does draw on the former and assumes an appreciation of the basic principles of soil physics. Together they cover the broad range of soil physics, providing a welcome integration of basic principles and practical applications.

Fundamentals . . . treats the basic static and dynamic properties of the solid, liquid 